\title{
DETERMINAÇÃO DE ÁREA FOLIAR E RETENÇÃO DE LÍQUIDO POR FOLHAS DE CAFÉ EM PULVERIZAÇÃO A ALTO VOLUME
}

\author{
FERREIRA, Marcelo da Costa ${ }^{1}$ \\ ALANDIA, Rodrigo Alberto ${ }^{2}$ \\ CARVALHO, Giorge França Gomes de ${ }^{3}$ \\ BAGGIO, Mariah Valente ${ }^{4}$
}

Recebido em: 2009. 11.10

Aprovado em: 2009.12.14

ISSUE DOI: $10.3738 / 1982.2278-316$

RESUMO:- O objetivo do presente trabalho foi determinar a capacidade de retenção de diferentes caldas acaricidas, por folhas de café em pulverização a alto volume, bem como comparar dois métodos de determinação de área foliar. Foram comparadas caldas com abamectina, abamectina com óleo mineral nas concentrações de $1 \%, 1,5 \%$, e abamectina com óleo vegetal nas concentrações de $1 \%, 1,5 \%$, correspondendo a cinco tratamentos em quatro repetições. Foram também comparados dois métodos de determinação da área foliar, correspondentes ao método gravimétrico e à análise de folhas digitalizadas. Por meio dos resultados obtidos foi possível concluir que o uso de adjuvante possibilita a redução do volume de calda e que adjuvantes à base de óleos nas concentrações utilizadas neste trabalho não diferem significativamente quanto à retenção de calda pela folha.

Palavras-chave: Retenção foliar. Café. Adjuvantes.

SUMMARY: The aim of this study was to determine the retention capacity of different moistures of acaricides, by spraying leaves of coffee in the high-volume, and compare two methods for determining leaf area. Were compared spraying liquids with abamectin, abamectin with mineral oil in concentrations of $1 \%, 1.5 \%$, and abamectin with vegetable oil in concentrations of $1 \%, 1.5 \%$, corresponding to five treatments in four repetitions. It was also compared two methods for determining the leaf area, which were gravimetric method and analysis of digitized leaves. Through the results it could be concluded that the use of adjuvant allows a reduction in the amount of spraying liquid and that adjuvants containing oils in the concentrations used in this study did not differ significantly on the retention of the liquid by leaves.

Keywords: Leaf retention. Coffee. Adjuvant.

\section{INTRODUÇÃOO}

Na cultura do café há ácaros fitófagos que são considerados pragas de importância crescente, tendo em vista os danos qualitativos e quantitativos que ocasionam à este cultivo.

Seu controle tem sido realizado com o uso de produtos fitossanitários, por causa de sua economicidade e ação rápida (FRAGOSO et al., 2002).

Para a pulverização de acaricidas, tradicionalmente é utilizado o volume alto de calda, em que gotas finas são produzidas por pontas de pulverização de jato cônico. Desta forma,

\footnotetext{
${ }^{1}$ Livre-Docente - Tratamento Fitossanitário - FCAV-UNESP

${ }^{2}$ Mestrando em Agronomia - - FCAV-UNESP - e-mail: alandiaroman @ gmail.com

${ }^{3}$ Mestrando em Agronomia - - FCAV-UNESP

${ }^{4}$ Bacharel em Ciências Biológicas - FCAV-UNESP
} 
parte da calda pulverizada se perde por escorrimento e apenas uma parcela se mantém na superfície foliar, resultando em desperdício e poluição ambiental, onerando o agricultor pelos custos diretos e indiretos decorrentes desta prática (MATUO; BABA, 1981; RAMOS et al., 2006; FERNANDES; FERREIRA; MARTINELLI, 2005).

Dentre os custos diretos há o investimento na aquisição de uma quantidade de produtos a serem adicionados à água no tanque do pulverizador para compor a calda de pulverização. Estes, ao ficarem fora das plantas de café devido ao escorrimento, levarão a perdas financeiras, somando-se a isto o custo hora das máquinas e dos operadores, as perdas financeiras tornam-se ainda mais expressivas. Indiretamente, a calda que vai para o solo interferirá na biota ali presente. Além disto, poderá ser carreada pela ação do vento e da chuva, resultando em contaminações secundárias.

A utilização de espalhantes-adesivos como adjuvantes em caldas a serem pulverizadas é comum e deve pretender o aumento da eficácia dos produtos fitossanitários aspergidos a campo. Todavia, tais substâncias promovem alterações nas propriedades da calda, como por exemplo, redução de sua tensão superficial, sendo que a quantidade de líquido retida na folha será menor em pulverizações a alto volume (MATUO; NAKAMURA; ALMEIDA, 1989; RUIZ; MATUO, 1994). A taxa de escorrimento também pode variar em função da área foliar do cultivo tratado, Matuo; Baba (1981) relatam que folhas de citros com áreas menores retêm proporcionalmente, maior volume de calda por unidade de área.

Menores volumes de aplicação, que não causem escorrimento podem resultar em cobertura da planta alvo, insuficiente para uma boa eficácia de tratamento realizado. Fernandes, Ferreira e Martinelli (2005) constataram que seria necessária uma cobertura entre 30 e $40 \%$ do alvo pela calda pulverizada para uma mortalidade do ácaro Brevipalpus phoenicis superior a $85 \%$ em plantas de café.

Visando o equilíbrio entre a redução do volume para tornar a aplicação mais econômica e segura com a manutenção da eficácia do tratamento, o agricultor pode lançar mão de agentes tenso-ativos adicionados à calda. O não ajuste do volume de aplicação quando da adição de adjuvantes resultará em ainda menor retenção da calda com consequente aumento do prejuízo financeiro e impacto ambiental.

Considerando, portanto, a importância de se conhecer a retenção máxima para caldas acaricidas em folhas de café, com e sem a adição de agentes tenso-ativos, realizou-se o presente trabalho com o objetivo de comparar dois métodos de determinação de área das folhas bem como determinar a capacidade de retenção de diferentes caldas acaricidas por folhas de café em pulverização a alto volume. 


\section{MATERIAL E MÉTODO}

O trabalho foi realizado no mês de outubro de 2008 no Departamento de Fitossanidade da UNESP, Campus de Jaboticabal. Foram determinadas a área foliar e a retenção de diferentes caldas acaricidas em folhas de café. Vinte folhas de Coffea arábica L. foram coletadas ao acaso da cultivar Mundo Novo com cinco anos de idade, localizada na fazenda experimental do campus. As folhas foram dividas em cinco grupos que correspondiam aos tratamentos, compostos por quatro repetições cada um.

\section{Determinação da área foliar}

Esta avaliação foi realizada com a finalidade de verificar a exatidão de métodos simples e aplicáveis a usuários comuns sem a necessidade de utilização de equipamentos complexos ou onerosos. Foram utilizados dois métodos de avaliação, o gravimétrico e a digitalização da imagem da folha, comparados pelo teste de Tukey a 5\% de probabilidade.

$\mathrm{Na}$ determinação da área pelo método gravimétrico foi utilizada a relação entre a massa de um quadrado de papel com área de $100 \mathrm{~cm}^{2}$, com a massa do desenho em espelho da folha do cafeeiro no mesmo tipo de papel. A área foliar foi determinada pela equação 1 :

$\mathrm{AF}=(\mathrm{M} * \mathrm{Af}) / \mathrm{m}(1)$ em que,

AF: Área foliar, $\mathrm{cm}^{2}$;

M: Massa do desenho da folha, g;

Af: Área do quadrado de papel, $\mathrm{cm}^{2}$, e

M: Massa do quadrado de papel, g.

Para determinar a área pela digitalização de imagem cada uma das folhas foi escaneada em escaner de mesa com resolução de 300 dpi e posteriormente processadas pelo software Quant v.0.1 (RODRIGUES, 2005).

\section{Retenção de líquido por folhas de café}

Penduraram-se as folhas pelo pecíolo, na vertical onde receberam em ambos os lados a pulverização com caldas acaricidas de duas pontas de jato cônico vazio, modelo TX-02. As pontas de pulverização estavam acopladas a um pulverizador costal pressurizado com $\mathrm{CO}_{2}$, mantendo pressão constante de $300 \mathrm{kPa}$. Previamente à pulverização, a balança com precisão de $1 \mathrm{mg}$ foi zerada para que desta forma pudesse ser obtida apenas a massa do volume pulverizado até o ponto de escorrimento. Assim cessado o escorrimento, observou-se os resultados na balança. Considerou-se a densidade do líquido igual a um. Portanto, realizou-se 
a conversão direta de massa para volume.

Foram testadas as seguintes caldas acaricidas:

a) -Abamectina

b) -Abamectina e Óleo Mineral na concentração de $1 \%$

c) -Abamectina e Óleo Mineral na concentração de 1,5\%

d) -Abamectina e Óleo Vegetal na concentração de $1 \%$

e) -Abamectina e Óleo Vegetal na concentração de 1,5\%

Foi escolhido o ingrediente ativo Abacmectina que é um acaricida/inseticida do grupo químico Avermectina, devido à ampla utilização pelo setor produtivo das culturas de café e citrus, principalmente para o controle do ácaro-da-leprose (Bravipalpus phoenicis).

A análise estatística utilizada foi o delineamento inteiramente casualisado em arranjo fatorial $2 \times 2$ com uma testemunha (acaricida pulverizado isoladamente) em quatro repetições. As médias foram comparadas pelo teste de Tukey a 5\% de probabilidade.

\section{RESULTADO E DISCUSSÃO}

Quando comparadas as formas de determinação de área foliar propostas neste trabalho, observa-se que não houve diferença estatística entre as metodologias descritas (Tabela 1), corroborando com os resultados obtidos por Silva, Leite e Ferreira (2008), onde comparando três métodos de avaliação de área foliar (Digitalização; Gravimétrico; Área do retângulo que circunscreve o limbo foliar) não encontraram diferença estatística entre os métodos avaliados.

Tabela 1. Comparação de metodologias para estimativa da área foliar

Metodologias Área foliar $\left(\mathrm{cm}^{2}\right)$

Gravimétrico 30,78 a

Digitalização de imagem $\quad 29,57$ a

\begin{tabular}{ll}
\hline Média & $\mathbf{3 0 , 1 7}$ \\
\hline C.V. (\%) & $\mathbf{2 2 , 9 7}$ \\
\hline Médias seguidas de mesma letra minúscula na coluna não diferem pelo Teste de Tukey. ${ }^{\text {NS. }}$ não significativo
\end{tabular}
$(\mathrm{P}>0,05)$; *: significativo $(\mathrm{P} \leq 0,05)$; **: significativo $(\mathrm{P} \leq 0,01), \mathrm{C} . \mathrm{V}$.: coeficiente de variação $(\%)$.

Um dos métodos mais utilizados é a estimativa da área foliar por meio de equações de regressão entre a área foliar real (AFR) e os parâmetros dimensionais das folhas (BIANCO; PITELLI; BIANCO, 2005; BARROS et al., 1973). Contudo, de acordo com Tavarez Júnior et al. (2002) este método não apresenta alta correlação com a área foliar real obtida pelo método destrutivo padrão, devido à baixa precisão. 
O método por digitalização de imagens apresenta um custo inicial maior em relação ao gravimétrico devido a necessidade de aquisição do conjunto composto por computador, escâner e software sendo que para a realização do gravimétrico, basta estar munido de papel, tesoura e balança de precisão, porém este pode apresentar um erro por falha humana já que é difícil de se padronizar o desenho e o corte do espelho da folha.

Na Figura 1, são apresentados os resultados da retenção foliar em folhas de cafeeiro.

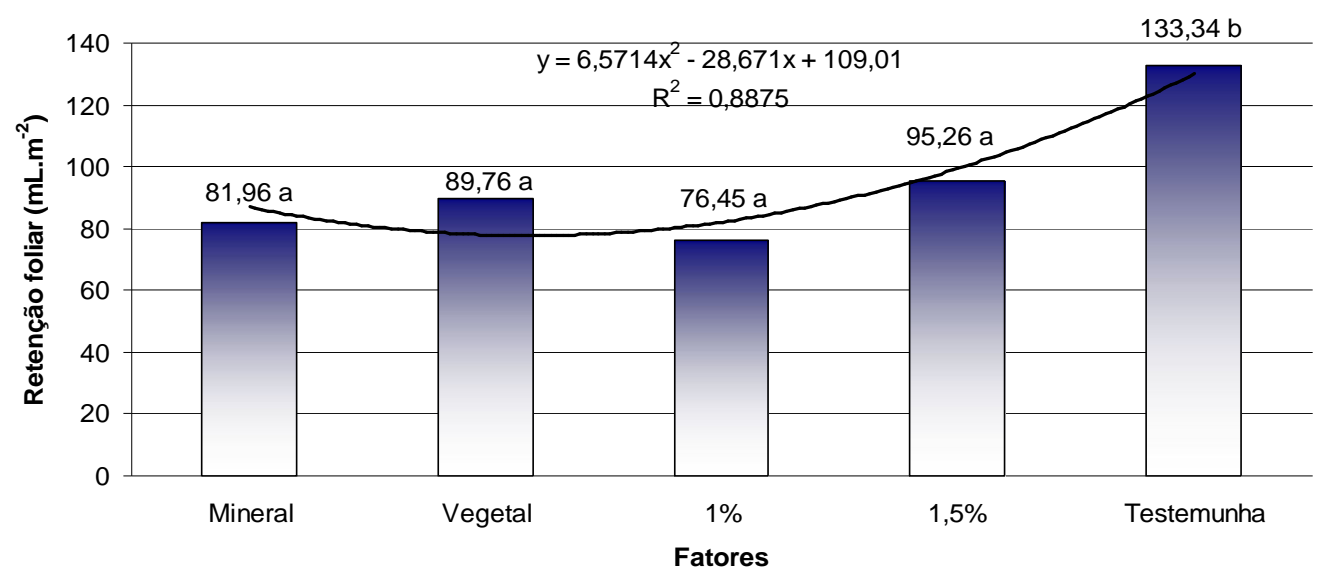

Figura 1. Retenção foliar de folhas de cafeeiro em função de adjuvantes e concentrações em calda acaricida

A adição dos adjuvantes à calda acaricida, nas duas concentrações reduziu significativamente a retenção de calda pelas folhas, em comparação à testemunha, o que significa que há a possibilidade da redução do volume de calda aplicado, em caso de adotar volumes convencionais com adição de adjuvante, o potencial de escorrimento será aumentado. Silva, Leite e Ferreira (2008) não obteve em seus resultados diferença estatística na retenção foliar da calda de pulverização composta por água e o adjuvante Haiten nas concentrações de 0,1 e 0,2\%. Miller e Butler Ellis (2000) constataram que mudanças nas propriedades químicas do líquido pulverizado, causadas pela adição de adjuvantes influenciam tanto no comportamento como no processo de formação das gotas, apresentando resultados semelhantes aos encontrados neste trabalho. Ocampo-ruiz (1992) também observou resultados semelhantes, com diminuição na capacidade das folhas de citros em reter a calda após a adição de surfatantes, sendo agronomicamente possível e viável a redução no volume aplicado uma vez que não foi alterada a porcentagem de mortalidade do ácaro. As divergências verificadas entre esta pesquisa e a realizada por Silva, Leite e Ferreira (2008) podem ser devido à natureza química dos adjuvantes e a adição do acaricida às caldas, não realizada por aqueles autores.

Para o fator adjuvante, o óleo vegetal foi estatisticamente igual ao óleo mineral sendo 
necessários estudos quanto ao custo/benefício, análise de periculosidade ambiental e riscos para os aplicadores de agrotóxicos para que sejam feitas as corretas recomendações.

A diminuição da retenção foi diretamente proporcional à diminuição da concentração (Figura 1), contrapondo com os valores obtidos por Ocampo-ruiz (1992), uma vez que este avaliou a retenção do acaricida propargite na cultura do citros, adicionando surfatantes a três concentrações e apesar de observar reduções significativas na retenção de calda, a quantidade retida pelas folhas foi inversamente proporcional ao aumento na concentração destes produtos. Em valores absolutos o uso da concentração de 1,0\% proporciona menor retenção foliar, o que significa um menor custo quanto à aquisição de adjuvantes para o tratamento fitossanitário em cafeeiro.

Avaliando o efeito do volume de calda interferindo na deposição foliar, Derksen e Sanderson (1996) observaram o aumento na uniformidade de deposição, proporcional ao aumento do volume de calda aplicado. Contudo, a área foliar apresenta uma capacidade de retenção limitada, sendo que o aumento acima do limite desta quantidade de calda aplicada, representa um aumento no custo de produção e contaminação ambiental.

\section{CONCLUSÃO}

- A utilização de adjuvante fez com que a retenção de calda pela folha fosse diminuída,

- Os dois métodos para determinação de área foliar são confiáveis, porém o gravimétrico é mais passivo de erro.

\section{AGRADECIMENTOS}

Ao Conselho Nacional de Desenvolvimento Tecnológico (CNPq) e a Coordenação de Aperfeiçoamento de Pessoal de Nivel Superior (CAPES) pelas concessões de bolsas aos primeiros autores.

\section{REFERÊNCIAS}

BARROS, R. S. et al. Determinação da área de folhas de café (Coffea arabica L. cv. Bourbon Amarelo). Revista Ceres, Viçosa, v. 20, n. 107, p. 44-52, 1973.

BIANCO, S.; PITELLI, R. A.; BIANCO, M. S. Estimativa da área foliar de Brachiaria plantaginea usando dimensões lineares do limbo foliar. Planta Daninha, Viçosa, v. 23, n. 4, p. 597-601, 2005. 
FERNANDES, A. P.; FERREIRA, M. C.; MARTINELLI, N. M. Mortalidade do ácaro Brevipalpus phoenicis em função da cobertura de pulverização de acaricidas, com e sem adjuvantes, em mudas de café. Revista de Agricultura. Piracicaba, v. 80, p. 173-187, 2005.

FRAGOSO, D. B.et al. Ação de inseticidas organofosforados utilizados no controle de Leucoptera coffeella (Guérin-Mèneville) (Lepidóptera: Lyonetiidae) sobre o ácaro predador Iphiseiodes zuluagai Denmark ; Muma (Acari: Phytoseiidae). Neotropical Entomology, Londrina, v. 31, n. 3, p. 463-467, 2002.

MATUO, T.; BABA, K. J. Retenção de líquido pelas folhas de citros em pulverização a alto volume. Científica, São Paulo, v. 9, n. 1, p. 97-104, 1981.

MATUO, T.; NAKAMURA, S. H.; ALMEIDA, A. Efeito de alguns adjuvantes da pulverização nas propriedades físicas do líquido. Summa Phytopathology, Botucatu, v. 15, p. 163-173, 1989.

MILLER, P. C. H.; BUTLER ELLIS, M. C. Effects of formulation on spray nozzle performance for applications from ground-based boom sprayers. Crop Protection, London, v. 19, n. 1, p. 609-615. 2000.

OCAMPO-RUIZ; R. A. Efeito de alguns espalhantes adesivos na retenção e ação do propargite sobre Brevipalpus phoenicis (Geijskes, 1939) em folhas de citrus. $1992.54 \mathrm{f}$. Dissertação (Mestrado em Entomologia Agrícola) - Faculdade de Ciências Agrárias e Veterinárias - Universidade Estadual Paulista, Jaboticabal, 1992.

RAMOS, H.et al. Manual de Tecnologia de Aplicação de Produtos Fitossanitários. São Paulo: ANDEF, 2006.

RUIZ, R. A. C.; MATUO, T. Efeito de espalhantes-adesivos na retenção e na ação do propagite sobre Brevipalpus phoenicis (Geijs.) em folhas de citros. An. Soc. Entomol., Brasil, v. 23, n. 2, p. 265-270, 1994.

RODRIGUES, G. J. Critérios rastreáveis na aplicação de inseticida no controle do bicho mineiro do cafeeiro. 2005. 108 f. Tese (Doutorado em Agronomia) - Universidade Federal de Viçosa.

SILVA, A.R.; LEITE, M.T.; FERREIRA, M.C. Estimativa da área foliar e capacidade de retenção de calda fitossanitária em cafeeiro. Bioscience Journal, Uberlândia, v. 24, n. 3, p. 66-73, 2008

TAVARES-JÚNIOR, J. E.et al. Análise comparativa de métodos de estimativa de área foliar em cafeeiro. Bragantia, Campinas, v. 61, n. 2, p. 199-203, 2002.

VALE, F. X. R. et al. Quant - A software to quantify plant disease severity. In:

INTERNATIONAL WORKSHOP ON PLANT DISEASE EPIDEMIOLOGY; The International Society of Plant Pathology, 2001, Ouro Preto, Brazil, Proceedings... v. 8, p. 160 
